
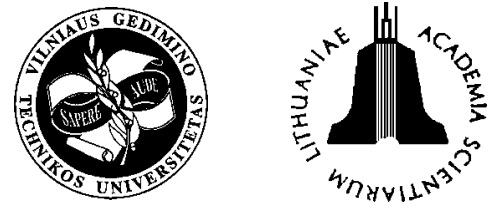

JOURNAL OF CIVIL ENGINEERING AND MANAGEMENT

http:/www.jcem.vgtu.lt

2004, Vol X, No 4, 311-316

\title{
NON-LINEAR 3D MODELLING OF RC SLAB PUNCHING SHEAR FAILURE
}

\author{
Povilas Vainiunas ${ }^{1}$, Vladimiras Popovas ${ }^{2}$, Andrej Jarmolajev ${ }^{3}$ \\ 1,2Vilnius Gediminas Technical University, Saulètekio al. 11, LT-10223 Vilnius, Lithuania. \\ E-mail: povva@st.vtu.lt; vlad@inre.lt3UAB “IN RE”, Lukiškiu g. 3, 6th floor, Vilnius, Lithuania. \\ E-mail: andrej@inre.lt
}

Received 14 July 2004; accepted 18 Nov 2004

\begin{abstract}
Modern technologies of 3D computer modelling with the help of finite-element methods of numerical analysis in non-linear aproach enable a reliable simulation of real reinforced concrete slabs behaviour under the conditions of complicated stress-strain state in all the stages of their behaviour under loading, including a stage of elasticity-plasticity state in concrete and reinforcement as well as formation and development of destruction mechanism. Numerical methods of modelling of critical behaviour of structures go beyond the borders of scientific research, being increasingly applied for solving non-trivial engineering tasks when it becomes evident that possibilities of analytical approach, acceptable for the existing design codes are not sufficient. In such a case an exceptional attention is to be paid for verification of calculated models against experimental research of similar numeric models. This article reviews a case of complex experimental-theoretical and numerical calculation and analysis methods applied for a reinforced concrete floor slab and column connection. The object of research is of exceptional interest as for practical calculation methods for this type of constructions following design norms of different countries revision and additional processing are necessary. The results of the reinforced concrete floor slab and column junction computer model non-linear numerical analysis are presented and compared with the results of an experimental study.
\end{abstract}

Keywords: design and analysis method, experimental study, 3D numerical modelling, non-linear analysis, punching shear, slab-column connection, crack pattern, strain/stress distribution, failure mechanism.

\section{Introduction}

Over the last years, numerical simulation has evolved from a specific research application to a fully accepted and widely used tool for product and process optimization. The rapidly growing use of numerical simulation is due both to the constantly increasing hardware performance and to the methodical software enhancements. Thus, the user community has grown considerably in recent past. Today, new challenges in view of a better integration of the simulation processes into the product development are arising. The objective is to accelerate the extraction of the knowledge accumulated in a wealth of simulations in such a way that it can be used to define product development standards and recommendations. It is becoming increasingly important to create efficient and effective simulation environments.

It is generally accepted that traditional practical design methods of concrete structures are based on the analytical empirical analysis approach. However, the analytical method had not evolved independently like a pure theory of structural mechanics. The improvement of the analysis method has been made on the base of the experimental results in order to reproduce real load-stressstrain relationships.
Recently, implementation of computer simulation methods in the field of analysis of building structures, including the ones of reinforced concrete, is becoming an increasingly effective tool used not only by scientific researchers but also practising engineers. Application of numerical analysis methods based on finite elements theory for solving practical tasks allow to perform virtual testing of structures and explore their behaviour under load and other effects under different conditions taking into account elastic and plastic behaviour of materials, appearance and development of splints, cracks and other damages (disintegration), and finally to simulate the failure mechanism and its consequences, and in this way to evaluate in objective way the working reserve of the structures [1-7].

Rapid development of computer simulation technologies makes us think about the accuracy and adequacy while describing actual behaviour of the structures, about the place of laboratory experimenting methods and prospects in the process of scientific research, and their relation to numerical experiment and analysis methods, about the limits for implementation of the latter and possibilities for practical usage. It is very important that before practical application FEM analysis methods should be 
verified and validated comparing the analysis results with reliable experimental data.

The goal of this paper is to present recent experiences in the field of computer simulation methods of concrete structures and their potential for practical engineering work, the role of analytical numerical analysis of concrete structures in relation to experimental studies and structural design methods.

\section{Research object}

Reinforced concrete plates supported on columns are easy to construct and thus are economical and widely used. However, flat plates are subjected to high local shear and tensile stresses around the column area. Since concrete is weak in tension, slabs without transverse reinforcement can be prone to brittle punching shear failures. Proper analysis of reinforced concrete shells and plates requires non-linear material formulations. The case of punching slab is an actual engineering task, where three-dimensional stress-strain state plays an important role for structural behaviour and failure mode.

During last five years a number of experimental and numerical investigations were applied by the authors in order to investigate design codes recommendations for punching shear calculation in terms of evaluation of some essential factors, which have an influence on punching shear behaviour and affect failure mode [8-11].

For practical design applications analytical design formulation based on theoretical experimental approach is accepted. Commonly main design aim of reinforced concrete slabs near the support zone is to avoid brittle and rapid punching failure mode. Comparing different punching shear strength analytical calculation methods one may find that most national design codes deal only with evaluation of concrete strength basically expressed by tensile strength and shear reinforcement within some specific area around the column support, so-called punching pyramid [12-16]. While there are more significant factors, that may have an influence on punching resistance like amount of flexural longitudinal reinforcement distributed within the support zone, bending moment and shear force transfer between slab and column, span to slab depth ratio, slab thickness and column depth ratio, etc.

The model of slab-column connection is presented and the features of the proposed formulation of non-linear 3D numerical analysis are discussed which can accurately simulate the case of punching shear behaviour, visualise crack pattern and strain-stress distribution inside the slab-column connection and finally take this mechanism for evaluation of analytical design equation.

\section{Experimental and analytical study}

Theoretical and experimental investigation of the flat slab to column connection model was performed at
VGTU Reinforced Concrete Structures Research Laboratory [11]. The objective of these investigation was as follows: to perform comparative analysis of slabs overlay punching shear strength calculation according to design norms used in Lithuania and neighbouring countries as well as Eurocode [12], to determine the main factors that condition this index and to perform experimental study on slabs punching shear as well as to compare the results with theoretical ones.

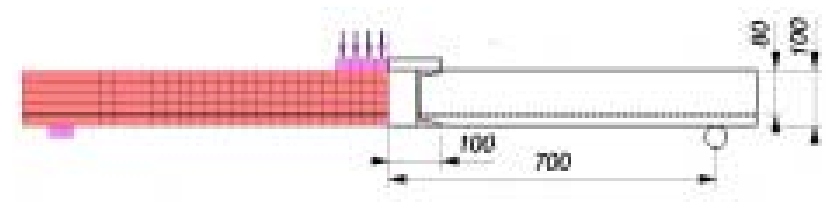

Fig 1. General view of the slab specimen (inverted)

The effect of longitudinal reinforcement ratio on punching shear behaviour in the tension area was analysed. Two series of similar rectangular slab series (PL I - 4 specimens and PL II - 5 specimens) were tested. Dimensions of the specimen are illustrated in Fig 1. The slabs were reinforced by mesh only in the upper area (under tension) using the following reinforcement ratios: $\rho=0$ (check specimen), $\rho=0,4, \rho=0,5, \rho=1,0$, $\rho=2,0$. The concrete strength of the 1 st and 2 nd specimens series respectively was as follows: cubic $f_{\text {cm,cube }}=39,85 \mathrm{MPa}$ and $f_{\text {cm,cube }}=32,11 \mathrm{MPa}$; prismatic $f_{\mathrm{cm}}=29,1 \mathrm{MPa}$ ir $f_{\mathrm{cm}}=23,7 \mathrm{MPa}$

Table 1. Comparision of experimental and analitical results

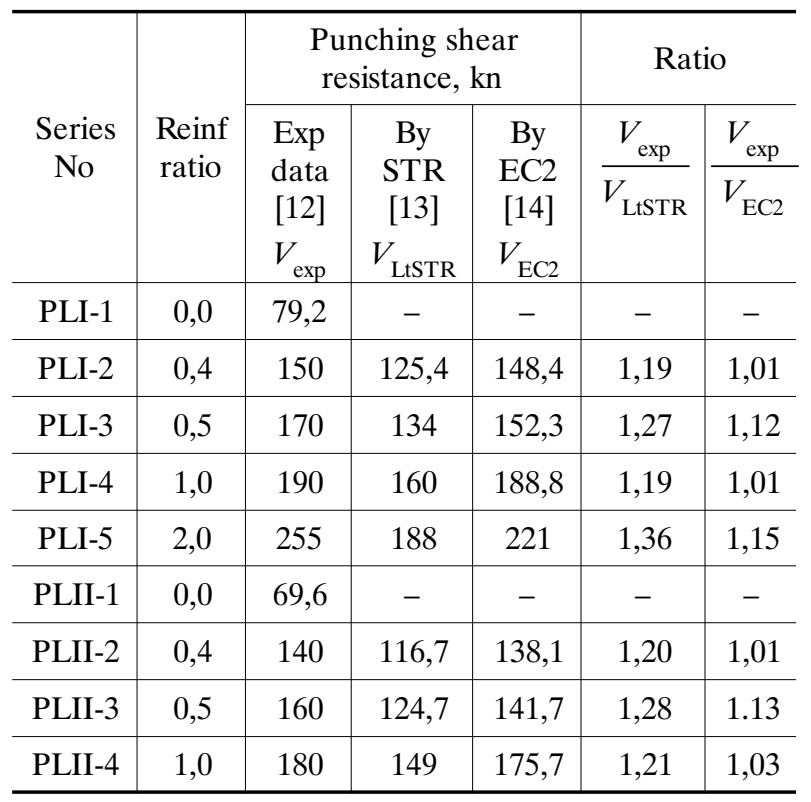

These experimental results have been compared to theoretical ones (Table 1). The following codes of practice were used for calculation: Lithuanian national reinforced concrete structures design code (project) STR 2.05.05:2004 [16] and Eurocode EC2 final case [12]. In the project of Lithuanian code it is proposed to apply 
EC2 calculation methodology, but the inclination angle of punched pyramid is to be taken not as $26,6^{0}(2,0 \mathrm{~d})$, but as $33,7^{0}(1,5 \mathrm{~d})$. When calculating theoretical failure load, the following is valid: $\gamma_{\mathrm{c}}=1,0, k=2,0, f_{\mathrm{ck}}=f_{\text {ckm }}$ and $\sigma_{\mathrm{sp}}=0$.

\section{Three-dimensional finite element model}

Analysis of punching shear failure was applied in order to simulate numerically behaviour of slab-column connection and to compare the failure mechanism with the experimental study and design results. Non-linear three-dimensional analysis (3D-FEM analysis) was performed using finite element software program MSC Marc [17-19].

To investigate the effect of longitudinal reinforcement ratio on punching shear behavior, two series of experimental slab specimens with different reinforcement ratio, were modeled. Fig 1 shows the experimental specimen and numerical model which were identical. The analytical model was taken as a quarter of the experimental specimen due to its symmetrical support conditions. FE mesh model with boundary loading conditions is shown in Fig 2 a. Since the corner lift-up of the experimental specimen was not restricted, the nodal displacement along the support within $100 \mathrm{~mm}$ from the edge was not restricted in vertical direction.

Reinforcing mesh was represented by Rebar FE placed only in the working area and near the supports (Fig 2b). Because concrete is mostly used in conjunction with steel reinforcement, an accurate analysis requires consideration of the components forming the composite structure. Steel reinforcement bars were introduced as

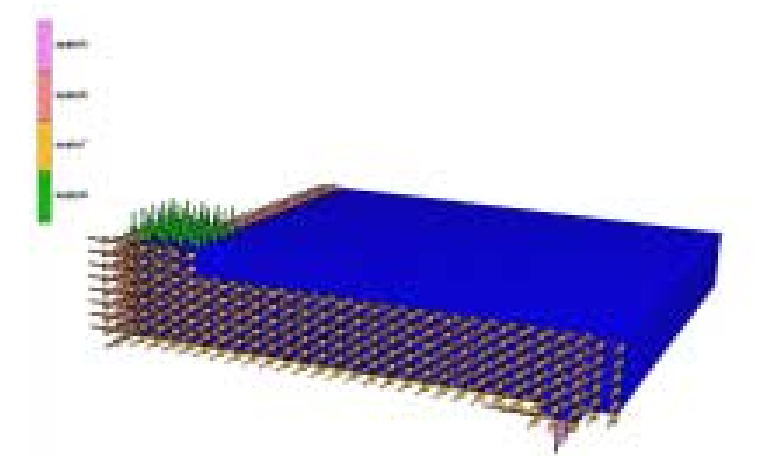

a)

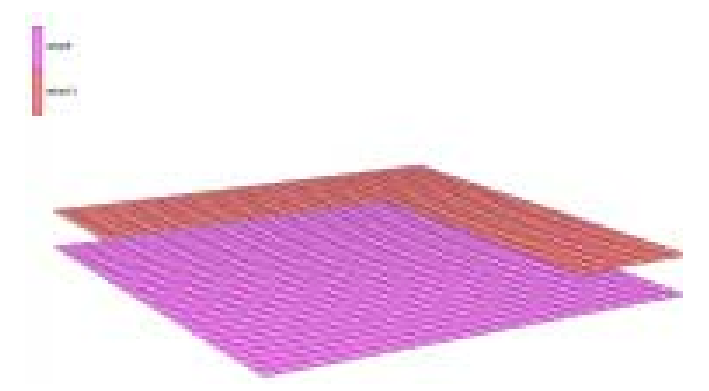

b)

Fig 2. 3D FE slab model with boundary and loading conditions (a); reinforcing mesh FE model (b) rebar elements. Rebar finite element was hollow, isoparametric 4-node membrane in which single strain members such as reinforcing rods can be placed. The element was then used in conjunction with the 4-node membrane to represent bar reinforced composite materials like reinforced concrete. This technique allows the rebar to be represented accurately with respect to their stress distribution, so that separate constitutive theories can be used in each case of material (for example, cracking concrete and yield rebar).

\section{Non-linear material model}

The choice of adequate material model for numerical simulation is the most important aspect in FEM analysis method to establish the "right" rules for structure behaviour. Concrete is a complex composite material with expressed non-linear response under loading conditions. The material model used for the analysis is described below.

MSC.Marc can handle concrete and other low-tension material models. The concrete model was a threedimensional, rate-independent model with a bounding surface [20-22]. The model adopts a scalar representation of the damage related to the strain and stress states of the material. The bounding surface in the stress space shrinks uniformly as the damage due to strain softening and/or tension cracks accumulates. The material parameters depend on the damage level, the hydrostatic pressure, and the distance between the current stress point and the bounding surface.

Analytical procedures that accurately determine stress and deformation states in concrete structures are complicated by several factors. Two such factors are the following: the low strength of concrete in tension that results in progressive cracking under increasing loads; the non-linear load-deformation response of concrete under multi-axial compression. The stress-strain relationship for short-term uniaxial compression loading was based on EC2 accepted concrete model specifications [16]. A typical uniaxial stress-strain diagram is shown in Fig 3.

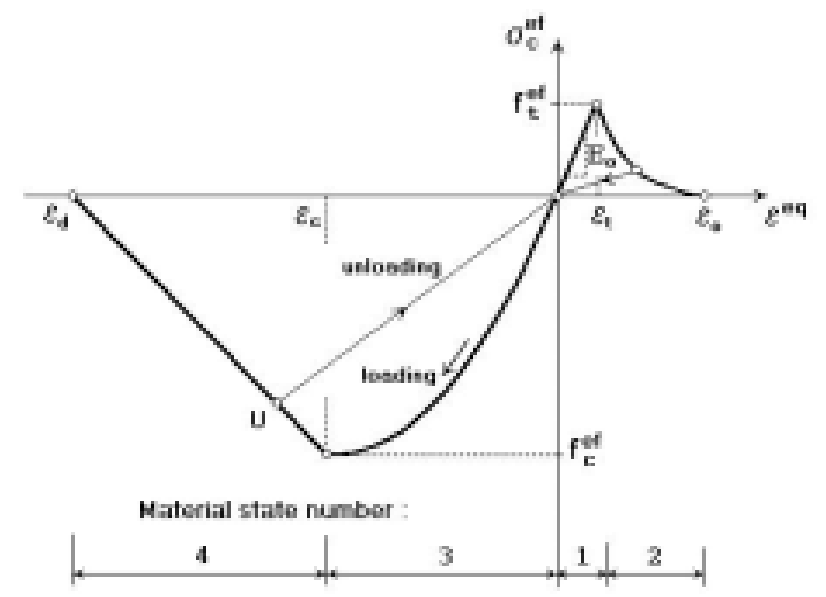

Fig 3. Concrete stress-strain relationship 
The material properties of both analytical empirical and numerical calculations are shown in Table 2

Table 2. Material properties for analysis

\begin{tabular}{l|c|c|c|l|r|r}
\hline \multicolumn{4}{c|}{ Concrete } & \multicolumn{3}{c}{ Reinforcement } \\
\hline$f_{\text {ck }}$ & $(\mathrm{MPa})$ & 20 & 25 & $f_{\text {uk }}$ & $(\mathrm{MPa})$ & 390 \\
\hline$f_{\text {ck,cube }}$ & $(\mathrm{MPa})$ & 25 & 30 & $f_{\text {yk }}$ & $(\mathrm{MPa})$ & 360 \\
\hline$f_{\text {cm }}$ & $(\mathrm{MPa})$ & 28 & 33 & $E_{\text {sm }}$ & $(\mathrm{GPa})$ & 210 \\
\hline$f_{\text {ctv }}$ & $(\mathrm{MPa})$ & 2.2 & 2.6 & & & \\
\hline$E_{\mathrm{cmb}}$ & $(\mathrm{GPa})$ & 30 & 31 & & & \\
\hline
\end{tabular}

\section{Numerical analysis results and discussion}

Numerical analysis results of punching shear strength of slab-column connection are shown in Fig 4 in comparison with the experimental data. Good agreement between the experimental and analytical results is to be indicated. The difference between analytical peak loads and experimental one for low and medium range of reinforcement ratio lies within the limits $(+) 3-(-) 11 \%$ for the first and $(+) 3-(-) 6 \%$ for the second specimens series.

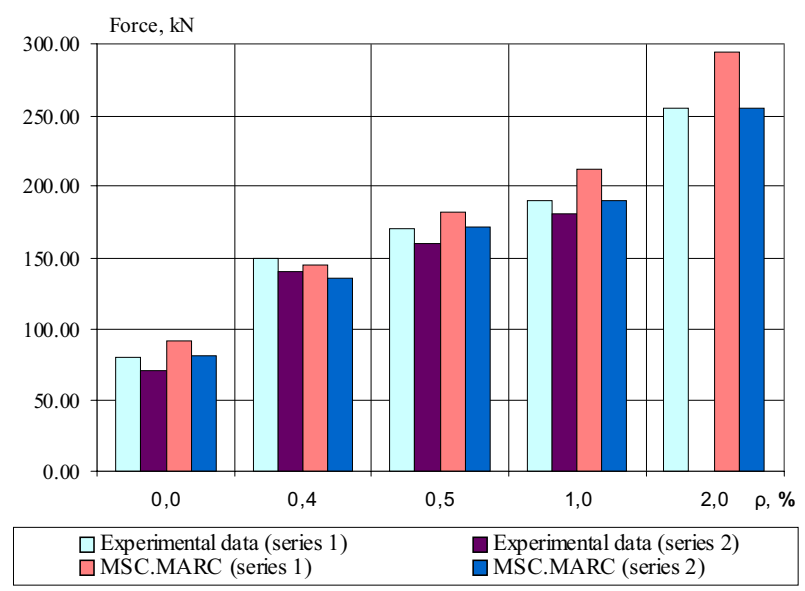

Fig 4. Numerical analysis and experimental results of slabcolumn connection punching shear load bearing capacity

\subsection{Load-displacement relationship}

Fig 5 shows a typical deformed shape and Fig 6 a load displacement curve of numerical model during the loading history. The peaks and drops of punching force show the appearance and development of shear cracks which were indicated in early stages of loading (about $50 \%$ of load bearing capacity). General trend of a bigger stiffness of numerical model, which led to bigger punching shear strength in comparison with experimental data should be accepted.

\subsection{Stress distribution and failure process}

Fig 7, in addition to damage process description, shows the failure stress distribution along depth and width

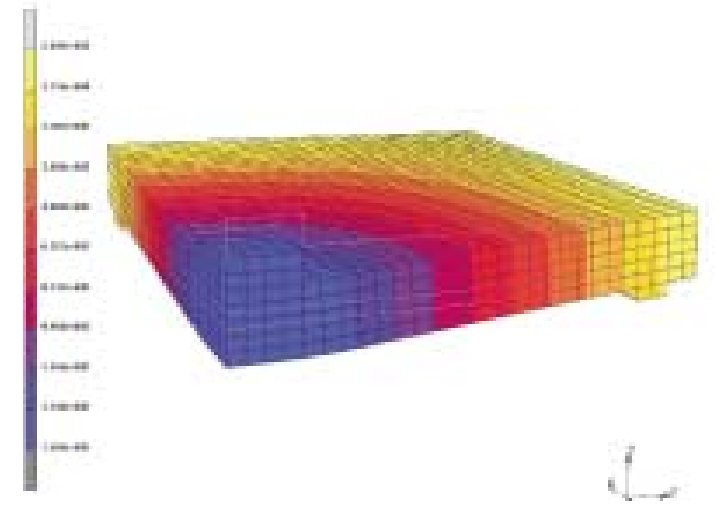

Fig 5. Deformed shape of analytical model

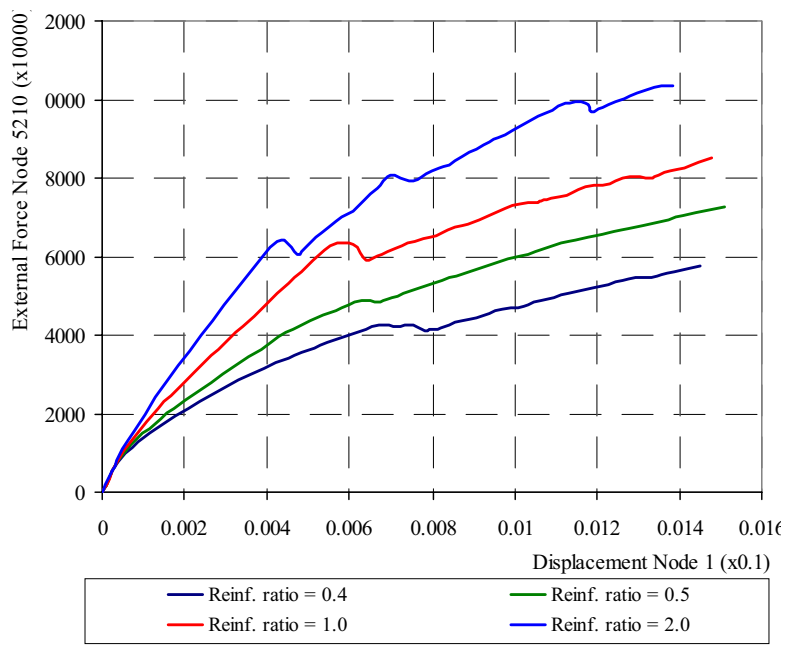

Fig 6. Load-displacement diagram of analytical model

of the specimen model. The crack pattern observed during numerical modelling was specific for punching shear failure mode because diagonal cracks spread from loading plate to the bottom. It was established that at first bending cracks in tension zone (bottom surface) of the slab initiate and propagate, forming the crack area similar to concentric circle (Fig 8 a). After that crack area reached the upper surface of slab and crack planes start to appear around the loading plate (Fig 8b). Finally cracking occurs around the loading plate and failure occurs with the reduction of load (Fig 8c).

Limit yield stress was achieved in reinforcement before the failure (Fig 7). Clear bending effect in combination with the punching shear failure mechanism was established. It is obvious that tensile reinforcement plays a significant role in the behaviour of slab-column connection subjected to punching force.

\section{Conclusions}

Non-linear finite element analysis based on advanced 3D models can be effectively used for the simulation of a real behaviour of reinforced concrete structures; it allows to perform virtual testing of structures and explore 
a)

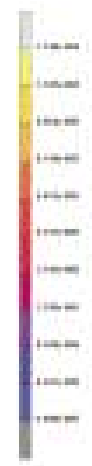

b)
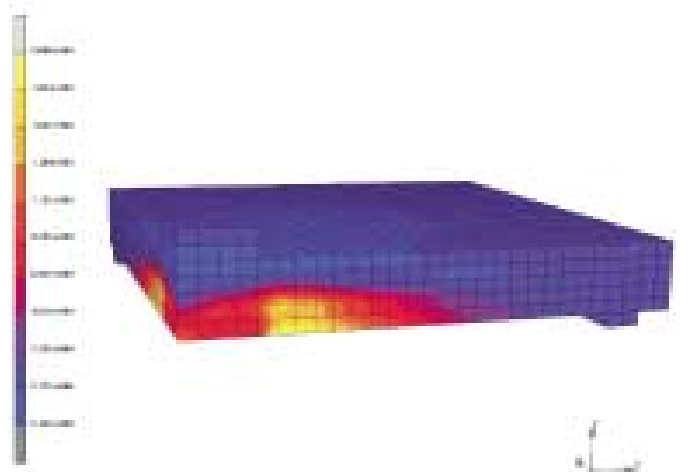

c)

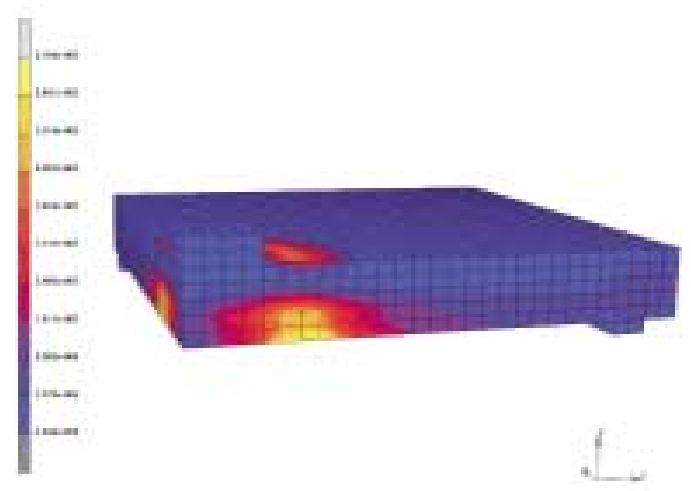

Fig 7. Stress distribution in concrete body in $3 \mathrm{a}, 22 \mathrm{~b}$, 50 c loading iterations

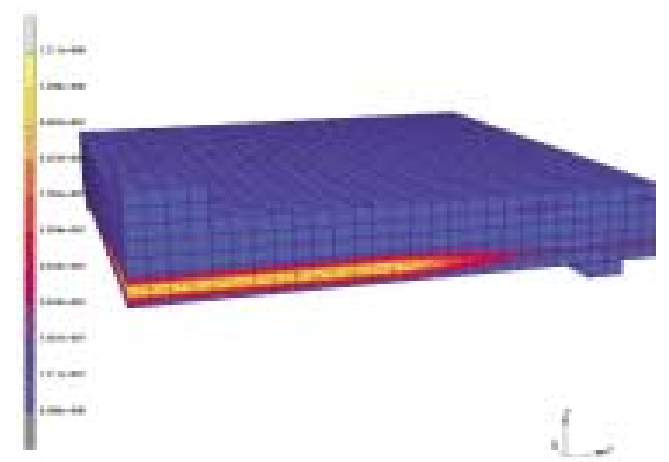

Fig 8. Stress in tension reinforcement before failure their behaviour under load and other effects under different conditions.

It is very important that before a practical application the FEM analysis methods should be verified and validated comparing the analysis results with reliable experiment data.

The choice of adequate material model for numerical simulation is the most important aspect in FEM analysis method to establish the "right" rules for structure behaviour.

Good agreement between numerical analysis results of punching shear strength of slab-column connection model and experimental data is to be indicated. The difference between analytical peak loads and experimental one for low and medium range of reinforcement ratio lies within the limits $(+) 3-(-) 11 \%$ for the first and $(+) 3-(-) 6 \%$ for the second specimens series.

It was established that at first bending cracks in tension zone (bottom surface) of the slab initiate and propagate, forming the crack area similar to concentric circle. After that crack area reached upper surface of slab and crack planes start to appear around the loading plate. Finally cracking occurs around the loading plate and failure occurs with the reduction of load.

Clear bending effect in combination with the punching shear failure mechanism was established. It is obvious that tensile reinforcement plays a significant role in slab-column connection behaviour subjected to punching force.

It can be assumed that suggested and validated advanced FEM 3D analysis model is suitable and reliable research tool for further detailed numerical investigations of reinforced concrete slab-column connection behaviour for punching shear.

\section{References}

1. Cervenka, V. Computer simulation of failure of concrete structures for practice: Session 13, failure mechanism and non-linear analysis for practice. In: Proc of the $1^{\text {st }}$ fib Congress Concrete Structures in the $21^{\text {st }}$ century, Osaka, 2002, p. 289-304.

2. Cervenka, V. Simulation of shear failure modes of RC structures. In: Proc of EURO-C. 1998, Badgastein, Austria, p. 833-838.

3. Hartl, H.; Handel, C. 3D finite element modeling of reinforced concrete structures: Session 13, Failure mechanism and non-linear analysis for practice. In: Proc. of the $1^{\text {st }}$ fib Congress Concrete Structures in the $21^{\text {st }}$ century, Osaka, 2002, p. 161-170.

4. Kaneko, Y.; Mita, A.; Mihashi, H.; Kanezashi, N. Practical use of non-linear analysis on damage detection of RC structures: Session 13, failure mechanism and non-linear analysis for practice. In: Proc of the $1^{\text {st }}$ fib Congress Concrete Structures in $21^{\text {st }}$ Century, Osaka, 2002, p. 1-14.

5. Tahashi, R.; Sato, Y.; Ueda, T. 3D FEM analysis of punching shear failure of steel-concrete sandwich slabs: Session 13, Failure mechanism and non-linear analysis for prac- 
tice. In: Proc of the $1^{\text {st }}$ fib Congress Concrete Structures in the $21^{\text {st }}$ century. Osaka, 2002, p. 139-144.

6. Wijaya, S.; Wendel, S. Simplified model for estimating punching resistance of RC slabs: Session 13, Failure mechanism and non-linear analysis for practice. In: Proc of the $1^{\text {st }}$ fib Congress Concrete Structures in the $21^{\text {st }}$ century. Osaka, 2002, p. 91-98.

7. Polak, M. A. Analysis of slab-column connections using shell finite elements: Session 13, Failure mechanism and non-linear analysis for practice. In: Proc of the $1^{\text {st }}$ fib Congress Concrete Structures in the $21^{\text {st }}$ century. Osaka, 2002, p.145-154.

8. Vainiūnas, P.; Popovas, A.; Jarmolajev, A. Punching shear behaviour analysis of RC flat floor slab-to-column connection. Journal of Civil Engineering and Management, 2002, Vol VIII, No 2, p. 77-82.

9. Vainiūnas, P.; Popovas, A.; Jarmolajev, A. Stress-strain analysis of beamless floor slab-to-column joint. Theoretical foundations of civil engineering $-X$ Polish-Ukrainian Transactions. Warsaw, June 2002, Vol II, p. 877-886.

10. Vainiūnas, P.; Popovas, A.; Jarmolajev, A. Analysis of castin-situ flat floor slab to column joint behaviour under punching. In: $7^{\text {th }}$ international conference "Modern building materials, structures and techniques". Abstracts of the $7^{\text {th }}$ international conference. Vilnius, Lithuania, 16-18 May 2001, p. 216-216.

11. Cimbaliuk, P. Stress state modelling and analysis of beamless floor slab in column collar zone. Master degree thesis. Supervisor Prof Dr P. Vainiūnas. VGTU, Faculty of Civil Engineering, Reinforced concrete and masonry structures department. Vilnius, 2003 p. 56.
12. prEn 1992-1-2. Eurocode 2: design of concrete structures Part 1.2; General rules - Structural fire design. European Committee for Standardisation, Brussels, July 2001, p. 102.

13. Baunormen Beton- und Stahlbetonbau DIN 1045, BeuthVertrieb GmbH, Berlin 30 Köln Frankfurt (Main), 1972.

14. SNiP 2.03.01-84 Concrete and reinforced concrete structures (Бетонные и железобетонные конструкции). Moscow, 1985.

15. Fintel, M. (ed), Handbook of concrete engineering, $2^{\text {nd }}$ ed, Van Nostrand Reinhold, New-York,1985.

16. Concrete and reinforced concrete structures (Betoninès ir gelžbetoninès konstrukcijos). STR 2.05.05:2004, Vilnius 2004. Project (in Lithuanian).

17. MSC Marc user's guide. Copyright 2003 MSC. Software Corporation.

18. MSC Marc Volume A. Theory and user Information. Copyright 2003 MSC. Software Corporation.

19. MSC Marc Volume B. Element library. Copyright 2003 MSC. Software Corporation.

20. Moussa, R. A. and Buykozturk, O. Bounding surface model for concrete. Nuclear Engineering and Design, 1990, Vol 121, p. 113-125.

21. Chen, E.S.; Buykozturk, O. Damage model for concrete in multi-axial cyclic stress. J. of Engineering Mechanics, ASCE, 1985, p. 111 (6).

22. Buyukozturk, O. Non-linear analysis of reinforced concrete structures. Computers and Structures, 1977, 7, p. 149-156. 